This is an Accepted Manuscript of an article published by Taylor \& Francis in Perspectives: Studies on Translatology on 10/05/2018, available online:

https://www.tandfonline.com/10.1080/0907676X.2018.1459753.

\title{
Do Translation Memories Affect Translations? Final Results of the TRACE Project
}

Adrià Martín-Mor

Departament de Traducció i d'Interpretació i d'Estudis de l'Àsia Oriental

Universitat Autònoma de Barcelona

ORCID: 0000-0003-0842-3190

This work was supported by a Spanish Ministry of Science and Technology Grant [HUM/2006-04349/FIL].

This work was supported by the Departament de Traducció i d’Interpretació i d'Estudis de l'Àsia Oriental of the Universitat Autònoma de Barcelona. 


\section{Do Translation Memories Affect Translations? Final Results of the TRACE Project}

Since their appearance in the translation field, Computer-Assisted Translation (CAT) tools and notably Translation Memories (TMs) have drawn the attention of the academia. Research evidences have, for instance, pointed towards an increase in the translators' productivity when using TMs, and some scholars have warned about possible implications of their use. The TRACE project, carried out by the Tradumàtica research group at the Universitat Autònoma de Barcelona, set off to explore the possible effects of these tools on the translation product. This article focuses specifically on linguistic interference, a phenomenon which, it has been suggested, might be a translation universal. Through experimental research, using a multimethodological approach and a combination of different datagathering resources, translations were done, with and without TMs, by ninety subjects. The experiments provide interesting data on the distribution of interference according to the environment in which they are carried out, as well as on the differences between different translator profiles. ${ }^{1}$

Keywords: translation technologies, Computer-Assisted Translation, Translation Memories, linguistic interference, laws of translation, translation universals, experimental research, research methodology.

1 This article is based largely on Chapter 15 of the author's doctoral thesis (see Martín-Mor, 2011). 


\section{Introduction}

Previous research (Somers, 2003) has already shown that the use of TMs increases translators' productivity. However, there has been little research on their effect on the final text. This research, as part of the TRACE research project carried out by the Tradumàtica group, ${ }^{2}$ compares translation with and without the use of TMs in order to detect differences between the translation products. To this end, an experimental study was designed using a multimethodological approach and several data-gathering resources. The ecological validity of translation situations was thoroughly taken into account throughout the research in order to ensure the reliability of the results. At the same time, different translators’ profiles are compared, since data was recorded from ninety subjects, including professional translators, in-house translators and novice translators.

\section{Goals}

The main goal of the TRACE project is to study whether TMs affect translations (Martín-Mor and Sánchez-Gijón, 2015). ${ }^{3}$ This article will look specifically at the phenomenon of linguistic interference through an analysis of translations done with and without TMs. In other words, the main research question of this article is: are translations done with TMs different from those done without TMs from the point of view of linguistic interference?

As part of a broader research, data about the process and the subjects was collected (the length of the translation process, subjects' gender, satisfaction, etc.).

2 Traducción Asistida, Calidad y Evaluación (TRACE). Project HUM-04349-FILO, 20062010, see www.tradumatica.net.

3 The project includes another study on the phenomenon of explicitation. 
Thanks to statistical analyses, the results obtained will be further investigated through triangulation.

This article is divided into four main parts: theoretical framework, methodological framework, results and discussion, and conclusions.

\section{Theoretical framework}

This section will establish the basis of the research through a review of the literature. Specifically, the notions of linguistic interference and translation memories, which are key concepts to the research, will be discussed.

\section{Linguistic interference}

Toury (1995) described interference as "phenomena pertaining to the make-up of the source text [which] tend to be transferred to the target text” (p. 272), and placed it conceptually under one of his universal laws of translation, the law of interference. Baker (1993, p. 243), on the contrary, when listing and identifying potential universals of translation, explicitly excluded linguistic interference, probably due to the fact that her method for investigating universals did not include the study of source texts (ST):

[Universal features of translation are] features which typically occur in translated text rather than original utterances and which are not the result of interference from specific linguistic systems. (1993, p. 243; my italics)

Therefore, these theories seem to concern the very essence of the phenomenon, i.e., whether it is a typical feature of translations (whether it is called general law or universal).

A more recent definition of interference is given by Franco Aixelá (2009, p. 75):

[T]he importation into the target text of lexical, syntactic, cultural or structural items typical of a different semiotic system and unusual or non-existent in the 
target context, at least as original instances of communication in the target language. (Franco Aixelá, 2009, p. 75)

A second question concerns the manifestations of the phenomenon. According to Toury (1995, p. 275), interference can adopt negative (“deviations from the normal, codified practices of the target system”) or positive forms ("greater likelihood of selecting features which do exist and are used in any case”).

This led Toury and other researchers to use two different names to refer to the two types of interference: transfer for the positive phenomenon and interference for the negative one, despite the fact that

\footnotetext{
After all, even though they do reflect features of another text, in another language, the results of positive transfer are hardly discernible from normal target-language productions. (Toury, 1995, p. 252; italics in the original)
}

This implies, as Pym (2008) notes, that "positive transfer appears normal in the target system” (p. 315). Transfer would be, therefore, invisible to the target reader, and would become "evident only when a translation is confronted with its source" (Toury, 1995, p. 275). However, if positive transfer cannot be distinguished from noninterference, as Mauranen (2004) points out, the differentiation loses meaning (p. 67): "In a normative sense, we might simply accept its manifestations [of positive transfer] as 'good translation'.”

This terminological variation still exists, even though some attempts (the "new way of looking at interference”, Eskola, 2004, p. 96) seek to abandon this duality:

[I]n the light of recent results it is important to see the impact of the source language not as a negative phenomenon to be avoided but rather as a neutral, abstract and statistical, potentially universal phenomenon, just as the concept of translationese has recently become more of a neutral term referring to features that tend to distinguish translations from original texts. (Eskola, 2004, p. 96) 
This "new way of looking at interference”, therefore, defends the neutrality of interference, and, as already stated by Toury, attributes the acceptability of interference to socio-cultural factors:

[T]olerance of interference - and hence the realization of interference itself have to do with the socio-cultural conditions in which translation is performed and consumed”. (Toury, 1995, p. 275; bold in the original)

The controversial status of linguistic interference, and the difficulties related to its operationalisation and measurement, probably affects the number of empirical studies devoted to it. Besides, the terminological variation hinders any attempt to systematise the phenomenon: Franco Aixelá (2009, p. 75) lists up to fourteen terms used as synonyms of interference, among which translationese and interlanguage, and other concepts such as fingerprints (Gellerstam, 2005) could be added to the list.

Furthermore, it should be noted that, if a broad definition of interference is assumed, potentially all studies dealing with the influence of the source text can be considered in some way as research on interference. This link becomes evident in many studies that did not focus originally on interference, such as Tirkkonen Condit's (2004) unique items hypothesis:

Translations tend to under-represent TL-specific, unique linguistic features and over-represent features that have a straightforward translation equivalent which are frequently used in the SL (functioning as some kind of stimuli in the source text). (Eskola, 2004, p. 83, my italics)

Kujamäki (2004) highlights that “these observations [...] are but one example of the functions of the «law of interference»" (p. 197), and Laviosa (2008) states that the “Unique Items Hypothesis [...] can be subsumed under Toury’s general law of interference as a particular case of negative discourse transfer” (p. 125). Even Olohan 
and Baker’s (2000) corpus study on the reporting that -initially, on the phenomenon of explicitation — is analysed by Pym (2008, p. 322) from the perspective of interference:

[T]he likely equivalents of reporting that appear to be obligatory rather than optional in virtually all the non-English languages I have asked about. It follows that the higher frequency of that in the translations could be a case of straight interference. But since the corpora are of English texts only, Baker's "comparable corpora” will never tell us about it. (Pym, 2008, p. 322; italics in the original)

Other studies do explicitly treat linguistic interference as a research variable (such as Castagnoli, 2009; Mauranen, 2004), and some attempts have been made to operationalise it. Franco Aixelá (2009) suggests the following categories: “words and phrases (lexical interference), forms (syntactic interference), specific cultural items (cultural interference [...]), or genre conventions (structural or pragmatic interference)” (p. 75). As explained in Operationalisation and measuring of linguistic interference, this categorisation was further expanded by adding phenomena found in the literature on contrastive linguistics of the specific language pair of the experiment.

Given that, according to the references cited in this section, the acceptability of linguistic interference is dynamic and depends on the norms of the target-language community, the analysis of the phenomenon was to be based on a more objectifiable element, formal resemblance, which would allow tackling interference from a neutral point of view, thus abandoning the correct/incorrect duality. ${ }^{4}$ Although results may shed some light on the phenomenon, the purpose of this study is not to prove or disprove its alleged universality, nor to investigate the acceptability of interference.

\section{Translation Memories}

Nowadays, Translation Memories are a key feature of most software used by translators

4 An additional study on the acceptability of interference was carried out subsequently

(Martín-Mor, 2011). 
(Martín-Mor, Piqué \& Sánchez-Gijón, 2016). These programmes allow the storage of source texts aligned with their translations in order to reuse them in the future. A key concept of TMs is segmentation, i.e. the division of texts into chunks, in accordance with the idea that limiting the length of the stored units will increase the possibility of finding future matches.

The above-mentioned chunks, or segments, use the typographic marks of the text (full stop, exclamation and interrogation marks, but also paragraph or page breaks, etc.) as stop characters indicating the end of a segment. In addition, these programmes usually allow users to define other stop characters (colon, semicolon, etc.). Figure 1 shows an example of how TM systems work.

Figure 1.

TMs have been proved to increase translators' productivity (around 30\%, according to Somers, 2003, p. 42), and have brought about changes in the translation workflow (e.g., project managers often analyse incoming translations against already translated texts stored in TMs when budgeting).

However, little research has been carried out regarding the effect of TMs on translation. It has been observed that TMs may negatively affect textual coherence, due to the use of previous translations by different translators with different styles (Bédard, 2000; as cited in O’Hagan, 2009, p. 50). Furthermore, according to Heyn (1998, p. 135), TMs may affect the readability and cohesion of translations. For example, in order to facilitate future matches, translators may avoid anaphoric or cataphoric references in their translations. Also Bowker (2002) warned that " [t]he rigidity of maintaining the same order and number of sentences in the target text as are found in the source text may affect the naturalness and quality of the translation” (p. 117).

In fact, the relationship between segmentation and interference seems to be one of the aspects that attracts researchers' interest, even if not all of them explicitly 
mention the phenomenon. Toury (1986) had already addressed the issue of interference at the level of the processing of the translation unit: "the segmentation of an SL utterance as actually performed by a translator may be taken as highly indicative [...] of the $[. .$.$] occurrence of discourse transfer.” (p. 83).$

The research by Dragsted (2004) is based on twelve translators (six students and six professionals) and studies from a cognitive point of view the effect of TMs on translations. Despite the fact that the study does not explicitly refer to interference, the link with the phenomenon seems to appear when the differences between processes with and without TMs are described (Dragsted, 2004): “Although the data were not as convincing as might have been expected, it was found that changes in the sentence structure were not performed to the same extent as under normal circumstances.” (p. 278).

In a later research, Dragsted (2006, p. 443) pointed out that TMs force users to process texts focusing on the segment, due to Automatic Segmentation (AS):

[...] sentence-by-sentence presentation inherent in TM systems [...] creates an unnaturally strong focus on the sentence, which affects the very task of translation (as well as the translation product). (Dragsted, 2006, p. 443)

Bloch (2005), on the other hand, explicitly mentions the relationship between AS and translation universals. The research is focused on three phenomena (“normalization, simplification and explicitation”), since "sentence splitting may be associated with all three universals”, but linguistic interference is not mentioned. Bloch analyses a multilingual corpus of about 7,000 segments made of source texts and their translations with TMs, and claims that there is "clear evidence for the existence of a splitting pattern in translations”: 
I believe [...] that sentence splitting in particular, and punctuation changes in general, are means deployed to serve translation strategies, rather than universals per se. In other words, they are manifestations of the universals. (Bloch, 2005)

Vilanova (2006) conducted a study with eight subjects (five professionals and three postgraduate students) on the differences between translations produced with and without TMs. One of her conclusions is that TMs cause more linguistic interference in syntax and punctuation, while no effects are found at the lexical level. As for segmentation, she states that "translators tend to make more changes in the paragraph structure and in the text as a whole when TMs are not used” (Vilanova, 2006, p. 14; my translation), in line with previous results in this field (Bloch, 2005, Dragsted, 2004 and 2006).

Pym (2008) seems to corroborate the link between interference and segmentation. He states, based on Toury's examples, that in the formulation of the law of interference, the term “make-up” seems to apply to a "set of segmentational and macrostructural features” (p. 316). Therefore, translations done with TMs may present a higher number of interference traces at the syntax level than those carried out without a TM, since "the segmentation patterns (the textual «make-up») tend to come straight from the source text as parsed by the software” (p. 323). As for the effect of technology on translations, Pym (2010 and 2011) observes that the "electronic communications we are dealing with are changing not just the way we translate but the way texts themselves operate” (2010), in the sense that TMs affect the "linearity" of texts:

The translating mind is thereby invited to work on one segment after the other, checking for terminological and phraseological consistency but not so easily checking, within this environment, for syntagmatic cohesion. (Pym, 2011, p. 3)

\section{Methodological framework}

This section describes the methodological framework, including the research variables 
and their operationalisation in measurable phenomena.

\section{Research design}

An experimental approach was designed in order to compare translations produced with and without the use of a TM system. In this section, independent and dependent variables as well as control variables will be explained. Data-gathering resources and the experimental set-up will also be presented.

The aim of the study is to find out if the use of TMs has an effect on the translation product.

Therefore, translation products are compared with respect to the occurrence of linguistic interference, and it will be investigated whether such differences (if any) can be attributed to different variables (mainly, translation with or without TM).

The statistical methods used in this study are mainly multivariate chi-square analyses. Multivariate analyses allow the simultaneous observation and analysis of several variables at a time. Some data about the process (perceived difficulty and autosatisfaction) was analysed in a subsequent stage of the research using bivariate chisquare analyses. All these variables will be described below in this section.

\section{Independent variables}

Translations were analysed based on the following variables: tools, texts, translator profile, tool order, duration of the translation, perceived difficulty and autosatisfaction.

Regarding tools (TMs), three environments were established:

- Environment 1 (E1): Translation without TMs. Translation is carried out with a word processor, as professional translators commonly do.

- Environment 2 (E2): Translation with a WYSIWYG translation memory system. Translation is carried out using a translation memory and a word processor, a 
common combination among translators. The WYSIWYG (What You See Is What You Get) functionality makes text formatting (such as bold text, italics, images, etc.) visible to the user. As explained in Translation Memories, TM systems use AS.

- Environment 3 (E3): Translation with a non-WYSIWYG translation memory system. Translation is carried out using a TM system that replaces text formatting and images by tags that contain this information, so that the translator works only with non-formatted text. Therefore, in E3, text formatting is not visible to the user and AS is used. ${ }^{5}$

Three source texts were designed for the experiment (in the three environments) by selecting and adapting existing texts so that they had similar characteristics, such as length (around 500 words each ${ }^{6}$ ), text genre (user manuals and marketing texts about technology products) and visual information (images and textual references). ${ }^{7}$ The texts were manipulated so that they included a preliminary set of indicators (or "rich points", in Pacte's (2005) terminology), which were chosen on the basis of a literature review, and which were adapted to the context of all three texts. Subsequently, in order to ensure comparability, the texts underwent specific research phases: exploratory test, external assessment and pilot study (see Dependent variable).

As for the topic, it was considered that the three texts should not cover the same topic, since that would allow a particular translator who was a specialist in that same

5 By selecting these three environments it was possible to analyse the eventual effects of the amount of visual information showed on the texts, even though this study will only focus on Automatic Segmentation.

6 According to the Asociación de Centros Especializados en Traducción (2005, p. 71), professional translators translate on average 3,000 words per day, which represents approximately 500 words per hour.

7 In this study, these texts will be referred to as T1, T2 and T3. 
topic to produce altered results in the study. In order to avoid this, three different topics were selected.

Subjects were classified in three profiles according to the following criteria. Freelance translators had at least three years' experience and translation accounted for at least $50 \%$ of their income. Novice translators had less than three years' experience, whereas in-house translators had been working in translation agencies between one and two years. ${ }^{8}$ Around 200 subjects sent a request to participate in the research, of which about half (90 English-Spanish translators) were finally selected (54 freelance, 18 novices and 18 in-house translators).

Finally, as will be explained in Control variables, the tool order was monitored in order to observe whether it affects translations. Furthermore, data about the process was recorded in order to triangulate the results, such as the duration of the task, the perceived difficulty and autosatisfaction (see Data gathered about the process).

\section{Dependent variable}

Linguistic interference constitutes the dependent variable and will be analysed based on translations of a set of preselected indicators. Linguistic interference has been operationalised — see Operationalisation and measuring of linguistic interferencethrough the categories shown in table 1:

Table 1.

Under category $\mathrm{O}$, the use of spelling conventions in the representation of numerals (e.g., thousand units) is analysed, especially in segments that contain no linguistic information, such as tables and images. The Obis category (typography and spelling — complementary) includes indicators regarding spelling conventions, such as

8 In-house translators had been working full-time in translation agencies for two years. That is the main difference compared with novice translators. 
the use of capital letters after a colon (:). Lexical transfer is analysed under categories $\mathrm{L}$ and Lbis (complementary), ${ }^{9}$ whereas category M, morphology and syntax, analyses the use of possessives. Category $\mathrm{C}$ includes indicators regarding gender-related aspects, and category E (encyclopedic) analyses indicators related to the extralinguistic knowledge of translators, such as references to place names. Finally, interference is observed at the macrotextual level, through coherence (“the overall structure of text information”) and cohesion (“the relationship between semantic and syntactic units of text”, Hurtado, 2001, p. 634, my translation). Details about the indicators chosen for these categories will be given in the section Operationalisation and measuring of linguistic interference. Table 2 shows the adapted typology of indicators and the categories they belong to.

Table 2.

\section{Control variables}

A number of variables were controlled in order to minimise unintended effects of such variables on the results of the study: the content of the TM, the segmentation settings, text and tool order and the instructions for the task.

The subjects were provided with an empty TM which could be reused across the three translations. The rationale behind this decision was to reproduce the working conditions of a professional environment while excluding the possibility that any previously stored segment could interfere with the translator's decisions.

TM systems were set up using the same parameters for all subjects. As for the segmentation settings, in E2 and E3, full stop, paragraph break, exclamation and interrogation marks, colon and semicolon were treated as stop characters. This is

9 The rationale for the use of two "complementary” categories can be found in Martín-Mor (2011, p. 131 and p. 134). 
especially relevant for indicators containing these marks (see Operationalisation and measuring of linguistic interference).

Tool and text order were randomized in order to avoid unintended effects, such as learning or warm-up effects. Table 3 shows text and tool orders.

\section{Table 3.}

The number of subjects allowing a full translation session with randomized tool and text orders was therefore eighteen. Five sessions (90 subjects) were scheduled in order to guarantee enough data for the statistical analysis.

Finally, in order to avoid differences in the instructions given to subjects —especially taking into account that there were more than a hundred participants over several sessions - - the instructions on the task were written and printed, so that all subjects received exactly the same information. Translators were given seventy minutes per task to "translate and revise", with no further mention of the way they should revise their translations (inside or outside the CAT tool).

\section{Data gathered about the process}

Data about the process was recorded during the experiment. The following data was registered in order to triangulate the results of the study: translation process data (from screencasting and keystroke logging software) and questionnaires eliciting data on the users' perception of the difficulty of each source text and their satisfaction with the translation. Further information was obtained through direct observation (see Datagathering resources).

\section{Data-gathering resources}

Although the primary data in the study is the actual translation product, the translation process was recorded as well. The use of data-gathering resources in this research is 
based largely on Martín-Mor (2007), where several data-gathering resources are evaluated. In particular, the following resources were used:

- $\quad$ Segments stored in TMs in E2 and E3, as these files may be useful as a backup copy.

- Video screen capture of the translation process for each subject through the use of screencasting software.

- Keystroke and mouse logs of each process through InputLog ${ }^{\circledR}$, versions 2.0 and 3.0 RC4 (Leijten and Van Waes, 2006).

- Post-translation questionnaires on the difficulty of the source texts and satisfaction with one’s own translation.

- Direct observation by the researchers present in the classroom.

It must be stressed that all data was collected through non-intrusive resources in order to respect the ecological validity of the translation situation. ${ }^{10}$

\section{Experimental set-up}

Five sessions were conducted between January and March 2009 at the Facultat de Traducció i d'Interpretació (Universitat Autònoma de Barcelona), both in morning and afternoon shifts. The sessions were structured in three phases of 70 minutes each, with two twenty minutes breaks in between. Written instructions were given to the subjects, although the researchers were present in the room while the experiment was taking place. At the end of each session, details about the process (through the abovementioned questionnaires), the product (resources in the computers) and about the subjects (the payment details) were collected by the research team and the participants gave their informed consent to the use of the data for research aims.

10 All the data gathered has been anonymised and made available at

\section{http://tradumatica.uab.cat/trace.}




\section{Operationalisation and measuring of linguistic interference}

The operationalisation of linguistic interference was based on previous work by Franco Aixelá (2009), and completed after three specific research phases. The first phase consisted of a literature review on comparative aspects of the English-Spanish language pair, so that the dependent variable could be translated in actual and tangible instances of linguistic interference (Ainaud, Espunya Prat and Pujol, 2003; López Guix and Minett Wilkinson, 1997; Montalt Resurrecció, 2005; Orozco Jutorán, 2006). In order to confirm the initial proposal and gather data about other indicators, an exploratory study was conducted, in which the texts containing the indicators were sent to three translation agencies as translation projects to be translated by professional translators in normal conditions (texts were to be translated as part of their job and using their usual resources), and only the project managers were informed about the final goal of the texts. The initial indicators were subsequently modified according to the results of the exploratory study, taking into account whether they had proved to be informative. This modified set was then validated by a committee of experts made up of seven translation researchers and university lecturers by means of a questionnaire in which they either accepted, refused or suggested indicators. ${ }^{11}$ The indicators that were not considered to be valid by the majority of the experts were discarded. Finally, the indicators were tested in a pilot study with eighteen students taking an MA Degree in Translation Technologies. This pilot study was conceived as a broader test of the methodology of the future experiment. ${ }^{12}$ The final set of indicators included one characteristic phenomenon for each of the categories described in Dependent variable.

11 The odd number of experts prevented the possibility of a tie-vote. See Martín-Mor (2011, p. 115 and p. 394) for a description of the external evaluation phase.

12 For a description of the methodological changes introduced in the experiment after the pilot study, see Martín-Mor (2012, p. 86). 
With regard to measuring linguistic interference, the study relies on an objective criterion: formal resemblance with the ST. In order to avoid subjectivity, a binary analysis was carried out. Thus, when the translation formally resembles the ST, this will be interpreted as "interference”. However, whenever a translation is formally different from the ST, and therefore distant, this will be interpreted as "no interference". The advantage of using a binary system is that it allows an objective analysis. The disadvantage, however, is that it does not allow for granularity when processing different degrees of interference at the resemblance level. Finally, non-measurable translations are those where linguistic interference cannot be observed, typically because of a missing indicator. Table 4 might help towards an understanding of the measurement of the dependent variable: two specific indicators, typography and spelling, and vocabulary, have been selected to illustrate the measurement of linguistic interference. $^{13}$

Table 4.

As shown in table 4, formally literal translations (capital letters after colon or a straightforward lexical equivalent) are processed as 1 (close translation, interference), whereas formally different translations are processed as 0 (distant translation, no interference), regardless of the degree of distance from the ST in order to meet the requirements of a binary analysis. Non-measurable translations are those where the indicator is missing in the translation (in the examples of the previous table, the capital letter after the colon). It could be objected that the absence of an indicator might be indicative of a translation strategy, and that considering these absences non measurable translations would imply dismissing important data. However, since no cognitive data was elicited in the study in order to tell whether such reformulations were a strategy to avoid interference, the interpretation of the reasons for these translations would imply a

13 Analyses of all translations are included in the appendices at the end of Martín-Mor (2011). 
certain degree of subjectivity on the part of the researcher. In order not to interpret the decisions of the translators where a reformulation took place, therefore, these kinds of translations were not included in the overall analysis, so that they would not alter the final results. Specific analyses were carried out instead among the non-measurable indicators, and interesting conclusions arose (see The effect of the tool).

\section{Results and discussion}

In this section the results of the research are discussed. For the sake of clarity, they are divided into results related to the translation product and results related to the translation process.

\section{Results related to the product}

The results of the statistical analysis show that the distribution of interference marks is affected by three variables: the tool used, the tool order and the translator's profile.

The effect of the tool

The analysis of the tool's impact on linguistic interference is directly related to the research question (are translations done with TMs different from those done without TMs from the point of view of linguistic interference?). While the analysis of the whole set of categories does not show significant differences between environments, there are three categories (typography and spelling-complementary, text conventions and encyclopedic) in which differences are statistically significant ( $p$ values $=<0.0001$; $0.0415 ; 0.0280)$.

Figure 2.

Furthermore, the results of the category of cohesion show big differences, even if the $\mathrm{p}$ value is not statistically significant (0.0648). 
The categories in figure 2, therefore, appear to be influenced to different extents by the environment. The results for the category that measures interference at the typography and spelling level show that translations done without the use of TMs display significantly less interference than those done with TMs. This category, which shows a highly significant probability value $(<0.0001)$, contains indicators in all texts related to the use of capital letters after a colon (see Operationalisation and measuring of linguistic interference). The reason for this high p value, therefore, most probably lies in the configuration of the TMs, since these use the colon as a stop character. In other words, environments 2 and 3 (see Independent variables) divide sentences with a colon into two segments, so the user's attention focuses just on the preceding, and not the succeeding, text, as shown in figure 3:

Figure 3.

Automatic Segmentation (AS), therefore, seems to cause more interference in this indicator. In contrast, in E1, due to the absence of AS, a higher number of translators start the succeeding sentence in lower case. It is worth mentioning that this category (Typography and Spelling - complementary) registers the highest number of reformulations of the study (such as the use of a comma, for instance, replacing the colon). Therefore, as previously argued, this data is not included in the global analysis so as not to alter the results with subjective interpretations on the part of the researcher. However, a separate analysis of these non-measurable indicators — which, in this category, account for more than a quarter of the data - reveals that reformulations appear more often in E1 (53.5\%) than in the other tools.

Table 5.

The numbers in table 5 indicate that translators may be more inclined to rephrase sentences in E1. The high number of non measurable indicators, therefore, reinforces the highly significant results of the statistical analysis. 
The category of cohesion (Co) shows a similar trend (less interference in E1), even if its probability value is not statistically significant. As in Obis, this category is closely related to the restructuring of segments of the ST according to the cohesive relationships between them — such as, for instance, replacing the full stops (see Dependent variable).

On the contrary, categories C (text conventions) and E (encyclopedic) show the opposite results: more interference in E1 (this implies, for example, not translating the references to elements of the software — the Run button— or not using the full form of the state name - PA versus Pensilvania — in the examples in Table 2). Therefore, as explained in the last paragraphs, there are two apparently divergent trends, two opposite effects of TMs on texts: in Obis and Co, more interference in TMs; in C and E, less interference in TMs.

Categories Obis and Co are related to the combining (or division) of segments, and so AS plays a crucial role in interference. On the contrary, the indicators in categories $\mathrm{C}$ and $\mathrm{E}$ are placed inside a single segment. A possible explanation would be that, since TMs require the user to perform an action for each segment of the text either translating the source segment, copying it or closing it without translation- the user's attention may be attracted to the open segment. Therefore, the very functioning of TMs (where the user's attention is focused on one segment at a time) might affect the dependent variable, apparently leading to less interference. The following figures illustrate the processing of a single indicator (specifically, category E; "Pittsburgh, PA") depending on the environment. 
Figure 4c

What the above figures show is how the translator's attention is drawn to the highlighted segment in E2 and E3 because of the very functioning of the TM system, whereas in E1 the same segment has a higher probability of being left unedited since the software does not compel the user to carry out any action in it.

These results seem to indicate that the way in which TM systems manage the translation process may affect the target texts, and appear to be in line with the abovementioned effect detected by Dragsted (2006), according to which "sentence-bysentence presentation inherent in TM systems [...] creates an unnaturally strong focus on the sentence, which affects the very task of translation” (p. 443).

What these categories share is a direct relationship with AS (especially related to the macrostructure of texts). In my opinion, the origin of the apparently contradictory results (for which a tentative explanation will be given in the conclusions) should not be sought in the characteristics of each category, but rather in a broader effect of TMs (and especially AS) on the way users process the translation unit. The fact that no significant results are found in other categories might be related to a weaker relationship between the other indicators and AS.

\section{The effect of the tool order}

Statistical analyses show that the distribution of interference is also influenced by the tool order. E1, for instance, obtains significantly less interference in the initial (i.e., when translated in the first place) than in the intermediate or final position ( $\mathrm{p}=0.0119)$. E3, on the contrary, obtains significantly more interference in the initial position $(p=0.0433)$. What is more interesting, however, is that the initial position of E1 and E3 
obtains extreme results: whereas E1 obtains the lowest number of interference traces, E3 obtains the highest number in the initial position, as shown in figure 5.

Figure 5.

This suggests that, considering isolated tasks with one tool, E1 causes less interference and E3, more. This indicates, moreover, that interference tends to increase along different positions in E1, while in E3 it tends to decrease. No significant results are found in E2.

Regarding the cause of these differences, one can rule out the possibility that they are due to the absence of a warm-up period, since specific analyses could not detect differences in the distribution of interference between texts translated in first, second and third place (Martín-Mor, 2011, p. 228). In my opinion, the fact that the differences shown by the previous figure are highly significant mainly in E1 could be tentatively attributed to the effect of the tool used in the first place. Should that be the case, TMs would affect subsequent translations carried out without TMs, and vice versa, translations carried out without TMs would affect, to a lesser extent, subsequent translations in TMs. ${ }^{14}$

\section{The translator's profile}

The results show differences in the distribution of interference by the subjects' profile. Novice translators' translations show more interference traces than freelance and inhouse’s translations (Martín-Mor, 2011, p. 246), which may come as no surprise. The mean of interference traces per text for freelance and in-house translators is quite similar (3 and 2.8, respectively), whereas the mean for novices is 4 , which makes the results statistically significant $(\mathrm{p}=0.0007)$.

14 Since the experiment was not designed to test such a hypothesis, a specific study would definitely be needed for this purpose. 
Nonetheless, more interesting results have also come to light. In category Co (cohesion), which contains indicators related to the joining and splitting of segments, freelance subjects show significantly less interference than both the other groups $(p=0.0408)$. This may suggest a greater awareness on the part of the freelancers of the effects of AS on cohesion or, more broadly, of the effects of CAT tools.

The answer to the research question (are translations done with TMs different from those done without TMs from the point of view of linguistic interference?) is provided, contrary to how it might appear, not by the analysis of the categories, but by the analysis of the differences between environments by different profiles (novice, freelancers and in-house translators). It is true, as can be seen in figure 6, that novices’ translations show significantly more interference in E2 $(p<0.0001)$ and E3 $(p=0.05)$ than in $\mathrm{E} 1(\mathrm{p}=0.1239)$.

Figure 6.

The fact that interference traces are evenly distributed among different profiles according to their competences shows that TMs do have an effect on linguistic interference, even if this effect is more visible on novice translators, and professional translators are able to compensate for these effects. Interestingly, the amount of interference traces among novices is much higher in E2 than in E3 — the p value (0.05) in E3, in fact, is almost statistically insignificant. Hypotheses for these results will be discussed in the following section.

\section{Results related to the translation process}

As mentioned previously, interesting results arise from the analysis of data relating to the translation process. This data might give valuable information when triangulated with the results of the previous section. This section will discuss the results on the duration of the translation task, the perceived difficulty and the satisfaction with the 
translation, which have been found to show statistically significant differences.

\section{Duration of the translation task}

Analyses of the length of the translation process showed that there is no correlation with the tool used nor with the number of interference traces. However, data showed very significant differences regarding the duration of translations according to the position of the task $(\mathrm{p}<0.0001)$. In the final translation, subjects took on average thirteen minutes less $(18.2 \%)$ to complete the translations compared with the first translation. This might be attributable to the experimental conditions of the translation situation (as time passes, translators devote less time to the translation tasks, be it as a result of a fatigue effect or because the nature of the task has already been internalized), or even by the absence of a warm-up task, which would have probably levelled out the duration of the three tasks.

Figure 7.

Perception of difficulty and satisfaction with the translation

Analyses of the responses to the questionnaires showed that translators generally considered T2 to be the most difficult text to translate. At the same time, analyses of the texts showed that T2 attracts significantly less interference traces than T1 (with the highest number of interference traces) and T3. Therefore, despite the fact that one might expect that a more difficult text would lead to more interference (because of comprehension problems, for example), the results point in the opposite direction.

The results also show a slight tendency (not statistically significant) of subjects to consider the translations carried out in first position to be more difficult. These results, furthermore, may be related to the findings that show that texts translated in the first position require more time. 
Regarding satisfaction with the translations, analyses showed that translators were slightly more satisfied with the translation of T1 than with the other two texts $(\mathrm{p}=$ 0.0497). However, it must be stressed that the concept of satisfaction might have been interpreted in different ways in the context of the questionnaire. Even if the aim was to find out which translation translators were most satisfied with, it is also true that the question might have been interpreted as which text was easier to translate.

\section{Conclusions}

The aim of this study was to study whether translations done with TMs are different from those done without TMs from the point of view of linguistic interference. According to the results of this study, translations might be different depending on the tool used, even if other variables have been found to significantly affect translations as well: the translator's profile and the tool order. After discussing these three variables, some concluding remarks will be also made with regard to translators' training.

Firstly, as regards the effect of the tool, differences in the distribution of interference were detected in some categories depending on the tool used. However, these effects, in my opinion, are not specific to any of the analysed categories, but are rather the consequence of a broader effect of TMs (and especially of AS) on the way translators process the translation unit. Apparently contradictory results were obtained for the effect of TMs, since in some categories it led to more interference and in some other categories it led to less interference. However, I believe that these are various manifestations of the same strong focus on the sentence caused by TMs, which, at the suprasentential level (when interference is related to joining or splitting segments; Pym, 2013, p. 496), might cause more interference in the macrostructure of texts, whereas at the sentence level it might lead to less interference. In other words, translators will most likely modify the content of a segment when working with a CAT tool (since it is more 
likely to attract their attention by requiring them to compulsorily perform an action before going on with the translation) but at the same time translators are less likely to modify the macrostructure of the text. ${ }^{15}$ Therefore this study seems to confirm the results of previous research (Dragsted, 2006), according to which "sentence-by-sentence presentation inherent in TM systems [...] creates an unnaturally strong focus on the sentence” (p. 443).

Secondly, it has been found that professional subjects are able to avoid this effect. This is shown by the fact that the translations of professional subjects (freelance and in-house translators) do not display significant differences depending on the environment used, whereas novices' translations do (more interference in E2 especially — and E3 than in E1). Considering that professional experience is the essential difference between the observed profiles, the effect that TMs have on translations might be closely linked to the instrumental sub-competence (Hurtado, 2001, p. 395). Moreover, translation competence seems to have an important role as well, since the novices' translations have more interference overall than experienced translators'.

Thirdly, as for the tool order, results strongly differ in consecutive tasks where the environment has been switched from a TM scenario to a text processor and, even if to a lesser extent (statistically less significant), from a text processor to a TM scenario. These results seem to indicate that TMs affect subsequent translations carried out without the use of TMs and vice versa. Specific research would be needed to confirm such a hypothesis.

Regarding translation training, the results of this study point to the importance of the notions of translation competence and instrumental sub-competence with regard to tolerance to interference. It is reasonable to think that adequate training (both in

15 Screencasts showing anonymised real translations of the mentioned indicators can be found at http://www.videos.tradumatica.net/as. 
translation and in translation technologies) and a certain degree of experience may result in greater awareness of interference. In this respect, the effect of TMs (especially that of AS) should be taken into account in the context of translator training.

Finally, some differences were detected between the number of interference traces in novices' translations, which were found to be much higher in E2 than in E3. Further studies should be carried out in order to confirm whether this difference is due to educational factors, like non-WYSIWYG TMs being less commonly included in translator training than WYSIWYG TMs. Should this be the case, it would explain why no significant differences are found between translations in E2 and E3 among the experienced subjects. Otherwise, the cause of these differences could be researched among software design differences, for example, in the amount of visual information offered by the tool. 
References

Asociación de Centros Especializados en Traducción. (2005). Estudio de situación del mercado español de servicios profesionales de traducción [Study of the situation of the Spanish market in professional translation services]. Madrid: ACT.

Ainaud, J., Espunya Prat, A. \& Pujol, D. (2003). Manual de traducció anglès-català [English-Catalan translation handbook]. Vic: Eumo.

Baker, M. (1993). Corpus linguistics and translation studies: Implications and applications. In M. Baker, G. Francis \& E. Tognini-Bonelli (Eds.), Text and technology: In honour of John Sinclair (pp. 233-250). Amsterdam: John Benjamins.

Bloch, I. (2005). Sentence splitting as an expression of translationese: seminar paper. Translation Studies Department, Bar Ilan University. Retrieved from: http://www.biu.ac.il/hu/stud-pub/tr/tr-pub/bloch-split.htm

Bowker, L. (2002). Computer-aided translation technology: A practical introduction. Ottawa: University of Ottawa Press.

Castagnoli, S. (2009). Regularities and variations in learner translations: A corpusbased study of conjunctive explicitation (Master's thesis). Dipartimento di Linguistica, Università di Pisa.

Dragsted, B. (2004). Segmentation in translation and translation memory systems: An empirical investigation of cognitive segmentation and effects of integrating a TM system into the translation process. Copenhagen: Samfundslitteratur.

Dragsted, B. (2006). Computer-aided translation as a distributed cognitive task. Pragmatics \& Cognition, 14(2), 443-464. doi: 10.1075/pc.14.2.17dra

Eskola, S. (2004). Untypical frequencies in translated language: A corpus-based study on a literary corpus of translated and non-translated Finnish. In A. Mauranen \& P. Kujamäki (Eds.), Translation universals: Do they exist? (pp. 83-99). Amsterdam: John Benjamins.

Franco Aixelá, J. (2009). An overview of interference in scientific and technical translation. The Journal of Specialised Translation, 11, 75-88.

Gellerstam, M. (2005). Fingerprints in translation. In G. Anderman \& M. Rogers (Eds.), In and out of English: For better, for worse (pp. 201-213). Buffalo: Multilingual Matters.

Hatim, B. \& Mason, I. (1990). Discourse and the translator. London: Longman. 
Heyn, M. (1998). Translation memories: Insights and prospects. In L. Bowker, M. Cronin, D. Kenny \& J. Pearson (Eds.), Unity in diversity? Current trends in translation studies (pp.123-136). Manchester: St. Jerome.

Hurtado, A. (2001). Traducción y traductología. Introducción a la traductología [Translation and translatology. Introduction to translation studies]. Madrid: Cátedra.

Kujamäki, P. (2004). What happens to 'unique items’ in learner’s translations? 'Theories' and 'concepts' as a challenge for novices' views on 'good translation’. In: A. Mauranen \& P. Kujamäki (Eds.), Translation universals. Do they exist? (pp. 187-204). Amsterdam: John Benjamins.

Laviosa, S. (2008). Description in the translation classroom. Universals as a case in point. In A. Pym, M. Shlesinger \& D. Simeoni (Eds.), Beyond descriptive translation studies. Investigations in homage to Gideon Toury (pp. 119-132). Amsterdam: John Benjamins.

Leijten, M. \& Van Waes, L. (2006). Inputlog: New perspectives on the logging of online writing. In K. P. H. Sullivan and E. Lindgren (Eds.), Studies in Writing: Vol. 18. Computer Key-Stroke Logging and Writing: Methods and Applications (p. 73). Oxford: Elsevier.

López Guix, J. G. \& Minett Wilkinson, J. (1997). Manual de traducción inglés castellano: teoría y práctica [English-Spanish translation handbook: theory and practice]. Barcelona: Gedisa.

Losse, K. (2008). Facebook: Achieving quality in a crowd-sourced translation environment. Paper presented at the Localisation Research Centre. Retrieved from: https://www.youtube.com/watch?v=os5OjH_yPoo

Malmkjær, K. (2005). Norms and Nature in Translation Studies. Synaps: Fagspråk, Kommunikasjon, Kulturkunnscap, 16, 13-19.

Mauranen, A. (2004). Corpora, universals and interference. In A. Mauranen \& P. Kujamäki (Eds.), Translation universals: Do they exist? (pp. 65-82). Amsterdam: John Benjamins.

Martín-Mor, A. (2007). Aproximació a les investigacions empíriques en traducció: aplicació al projecte TRACE [An approach to empirical research in translation: application to the TRACE project] (Master's thesis). Bellaterra: Departament de Traducció i d’Interpretació, Universitat Autònoma de Barcelona. Retrieved from: http://hdl.handle.net/2072/111962 
Martín-Mor, A. (2011). La interferència lingüística en entorns de Traducció Assistida per Ordinador: recerca empíricoexperimental [Linguistic interference in Computer Assisted Translation environments: experimental research] (PhD thesis). Bellaterra: Departament de Traducció i d’Interpretació, Universitat Autònoma de Barcelona. Retrieved from: http://tdx.cat/bitstream/handle/10803/83987/amm1de1.pdf

Martín-Mor, A. (2012). Le tecnologie della traduzione e il loro effetto nei testi. Design sperimentale e risultati preliminari di uno studio con strumenti CAT [Translation technologies and their effect in texts. Experimental design and preliminar results of a study with CAT tools]. Rivista Internazionale di Tecnica della Traduzione, 14, 79-94. Retrieved from: http://hdl.handle.net/10077/9780

Martín-Mor, A. \& Sánchez-Gijón, P. (2015). Differences between translations made with and without CAT tools: An empirical approach. In P. Sánchez-Gijón, O. Torres-Hostench \& B. Mesa-Lao (Eds.), Conducting Research in Translation Technologies (pp. 209-226). Oxford: Peter Lang.

Martín-Mor, A., Piqué, R. \& Sánchez-Gijón, P. (2016). Tradumàtica: Tecnologies de la Traducció [Tradumàtica: translation technologies]. Vic: Eumo.

Neunzig, W. (2007). Estudios empíricos en traducción: enfoques y métodos [Empirical studies in translation: approaches and methods]. Bellaterra: Departament de Traducció i d’Interpretació, Universitat Autònoma de Barcelona.

Montalt Resurrecció, V. (2005). Manual de traducció cientificotècnica [Scientific and technical translation handbook]. Vic: Eumo.

O’Hagan, M. (2009). Computer-aided translation (CAT). In M. Baker \& G. Saldanha (Eds.), Routledge encyclopedia of translation studies (pp. 48-51). London: Routledge.

Olohan, M. \& Baker, M. (2000). Reporting that in translated English. Evidence for subconscious processes of explicitation?. Across Languages and Cultures, 1(2), 141-158. doi: 10.1556/Acr.1.2000.2.1

Orozco Jutorán, M. (2006). Traducción del inglés al castellano: materiales de introducción a la traducción general directa [English to Spanish translation: introductory materials to general direct translation]. Bellaterra: Universitat Autònoma de Barcelona.

Pacte. (2005). Primeros resultados de un experimento sobre la Competencia Traductora [First results of an experiment on translation competence]. Proceedings of the II Congreso Internacional de la AIETI (Asociación Ibérica 
de Estudios de Traducción e Interpretación) 'Información y documentación’ (pp. 573-587). Madrid: Publicaciones de la Universidad Pontificia Comillas.. Pym, A. (2008). On Toury's laws of how translators translate. In A. Pym, M. Shlesinger \& D. Simeoni (Eds.), Beyond descriptive translation studies. Investigations in homage to Gideon Toury (pp. 311-328). Amsterdam: John Benjamins.

Pym, A. (2010). Technology and the translation professions Retrieved from https://www.facebook.com/photo.php?v=1238051727907

Pym, A. (2011). What technology does to translating. Translation \& Interpreting, 3(1), 1-9. Retrieved from http://www.trans-int.org/index.php/transint/article/view/121 Pym, A. (2013). Translation Skill-Sets in a Machine-Translation Age. Meta, 3, pp. 487503.

Somers, H. (Ed.). (2003). Computers and translation: A translator's guide. Amsterdam: John Benjamins.

Tirkkonen-Condit, S. (2004). Unique items: Over- or under-represented in translated language?. In A. Mauranen \& P. Kujamäki (Eds.), Translation universals: Do they exist? (pp. 177-184). Amsterdam: John Benjamins.

Tirkkonen-Condit, S. \& Mäkisalo, P. (2007). Cohesion in subtitles: A corpus-based study. Across Languages and Cultures, 8(2), 221-230.

Toury, G. (1995). Descriptive translation studies and beyond. Amsterdam: John Benjamins.

Vilanova, S. (2006). L'impacte de les tecnologies de traducció en el català tècnic [The impact of translation technologies in technical Catalan] (Master's thesis). Tarragona: Intercultural Studies Group, Universitat Rovira i Virgili. Retrieved from https://web.archive.org/web/20120629142119/http://isg.urv.es/publicity/ isg/projects/2006_PBR/final_report.pdf 


\begin{tabular}{|cc|}
\hline Code & Category \\
\hline O & $\begin{array}{c}\text { Typography and spelling } \\
\text { Typography and spelling }\end{array}$ \\
Obis & (complementary) \\
L & Vocabulary \\
Lbis & Vocabulary (complementary) \\
M & Morphology and syntax \\
C & Text conventions \\
E & Encyclopedic knowledge \\
Ca & Coherence \\
Co & Cohesion \\
\hline
\end{tabular}

Table 1. Categorization of linguistic interference. 


\begin{tabular}{|c|c|c|}
\hline Code & Category & Example \\
\hline $\mathrm{O}$ & Typography and spelling & Key 1,024 bits \\
\hline Obis & $\begin{array}{l}\text { Typography and spelling } \\
\text { (complementary) }\end{array}$ & $\begin{array}{l}\text { The file is } 13.7 \mathrm{MB} \text { : It may take some minutes to } \\
\text { download }\end{array}$ \\
\hline $\mathrm{L}$ & Vocabulary & $\begin{array}{l}\text { Use the drop down menus for easy input of patient } \\
\qquad \text { details. }\end{array}$ \\
\hline Lbis & Vocabulary (complementary) & Technical specifications \\
\hline M & Morphology and syntax & Double-click the $[\ldots .$.$] icon on your desktop$ \\
\hline $\mathrm{C}$ & Text conventions & [...] click the Run button \\
\hline $\mathrm{E}$ & Encyclopedic knowledge & Pittsburgh, $\underline{\mathrm{PA}}$ \\
\hline Сa & Coherence & $\begin{array}{c}{[\ldots] \text { please contact the author }[\ldots] \text {. The author and }} \\
\text { her team }\end{array}$ \\
\hline Co & Cohesion & No cost. No obligation. No Hassle. \\
\hline
\end{tabular}

Table 2. Examples of the categories. 


\begin{tabular}{|c|c|c|c|c|c|}
\hline Tool & Texts & Subjects & Tool & Texts & Subjects \\
\hline \multirow{3}{*}{ Tool order 1} & Text order 1 & 1 subject & \multirow{3}{*}{ Tool order 4} & Text order 1 & 1 subject \\
\hline & Text order 2 & 1 subject & & Text order 2 & 1 subject \\
\hline & Text order 3 & 1 subject & & Text order 3 & 1 subject \\
\hline \multirow{3}{*}{ Tool order 2} & Text order 1 & 1 subject & \multirow{3}{*}{ Tool order 5} & Text order 1 & 1 subject \\
\hline & Text order 2 & 1 subject & & Text order 2 & 1 subject \\
\hline & Text order 3 & 1 subject & & Text order 3 & 1 subject \\
\hline \multirow{3}{*}{ Tool order 3} & Text order 1 & 1 subject & \multirow{3}{*}{ Tool order 6} & Text order 1 & 1 subject \\
\hline & Text order 2 & 1 subject & & Text order 2 & 1 subject \\
\hline & Text order 3 & 1 subject & & Text order 3 & 1 subject \\
\hline \multicolumn{2}{|c|}{ Total } & 9 subjects & \multicolumn{2}{|c|}{ Total } & 9 subjects \\
\hline \multicolumn{6}{|c|}{ Total: 18 subjects } \\
\hline
\end{tabular}

Table 3. Text and tool combinations for a complete experimental session. 


\begin{tabular}{|c|c|c|c|}
\hline \multicolumn{2}{|c}{ Formal analysis } & \multicolumn{1}{c|}{ Typography and spelling } & Vocabulary \\
\hline \multirow{2}{*}{ ST } & & {$[\ldots] 4$ keys: If you [...] } & Specifications \\
\hline \multirow{2}{*}{ TT } & 1 (close to ST) & {$[\ldots] 4$ teclas: Si se [...] } & Especificaciones \\
\cline { 2 - 4 } & 0 (distant from ST) & {$[\ldots] 4$ teclas: si se [...] } & Características \\
\cline { 2 - 4 } & 99 (non-measurable) & {$[\ldots] 4$ teclas, que [...] } & $\varnothing$ \\
\hline
\end{tabular}

Table 4. Measurement of indicators. 
No. of non-measurables

\begin{tabular}{|l|l|}
\hline E1 & 38 \\
\hline E2 & 16 \\
\hline E3 & 17 \\
\hline Total & 71 \\
\hline
\end{tabular}

Table 5. Non-measurable translations in the Obis category.

37 
Figure 1. An example of a TM system (OmegaT), showing source (shaded in green) and target segments, and a fuzzy match (right) previously translated.

Figure 2. Categories in which the distribution of linguistic statistically differs between environments.

Figure 3. Example of segmentation and its effect on interference at the typography and spelling level.

Figure 4a, 4b, 4c. Comparison of the visualization of an indicator in E1 (upper left), E2 (upper right) and E3 (below).

Figure 5. Interference and tool order.

Figure 6. Profiles and interference.

Figure 7. Duration of the translation process. 